\title{
Preemptive Dexamethasone Reduces Pediatric Post-Tonsillectomy Pain: A Triple-Blind Randomized Clinical Trial
}

\author{
Rohollah Abbasi ${ }^{1}$, Javad Yazdani ${ }^{2}$, Mohammad Saeed Ahmadi ${ }^{1}$, Javaneh Jahanshahi ${ }^{3}$, \\ Mohamad Hossein Bakhshaei ${ }^{4}$, Abbas Moradi', Farnaz Hashemian3,* \\ ${ }^{I}$ Assistant Professor, Department of Ear-Nose-Throat Surgery, School of Medicine, Hamadan University of Medical Sciences, \\ Hamadan, Iran \\ ${ }^{2}$ Resident, Department of Ear-Nose-Throat Surgery, School of Medicine, Hamadan University of Medical Sciences, \\ Hamadan, Iran \\ ${ }^{3}$ Associate Professor, Department of Ear-Nose-Throat Surgery, School of Medicine, Hamadan University of Medical Sciences, \\ Hamadan, Iran \\ ${ }^{4}$ Associate Professor, Department of Anesthesiology, School of Medicine, Hamadan University of Medical Sciences, \\ Hamadan, Iran \\ ${ }^{5}$ Academic Member, Department of Community Medicine, School of Medicine, Hamadan University of Medical Sciences, \\ Hamadan, Iran \\ * Corresponding Author: Farnaz Hashemian, Department of Ear-Nose-Throat Surgery, School of Medicine, Hamadan \\ University of Medical Sciences, Hamadan, Iran.Email: hashemian@umsha.ac.ir
}

Received: 03.08.2019

Accepted: 17.11 .2019

\section{How to Cite this Article:}

Abbasi R, Yazdani J, Ahmadi

MS, Jahanshahi J, Bakhshaei

MH, Moradi A, Hashemian.F.

Preemptive Dexamethasone

Reduces Pediatric Post-

Tonsillectomy Pain: A Triple-

Blind Randomized Clinical

Trial. Avicenna J Clin Med.

2019; 26(3): 131-136. DOI

$10.29252 /$ ajcm.26.3.131

\section{Abstract}

Background and Objective: Adenotonsillectomy is one of the most commonly performed surgical procedures in children. Although this surgery is technically easy, it can run a high risk of serious complications, such as laryngeal spasm, laryngitis, bleeding, pain, and nausea. The present study aimed to assess the effect of preemptive dexamethasone on pediatric post tonsillectomy pain.

Materials and Methods: This triple-blinded clinical trial study involved a total number of 70 children within the age range of 3-15 years. They were candidates for adenotonsillectomy and were randomly assigned to two groups. One hour before the surgery, one group received intravenous dexamethasone $(0.1 \mathrm{mg} / \mathrm{kg})$ and the other group received distilled water intravenously. Patients' pain at $1,4,10$, and 24 hours after the surgery, initiation of soft-diet feeding and the prevalence of nausea and vomiting were evaluated in both groups. Data were analyzed in SPSS software (version 16).

Results: The total number of patients was 70 (35 in each group). Both groups were homogenous in terms of age and gender. In the intervention group, the mean score of pain in the first and fourth hours and the mean initiation time of soft- diet feeding were significantly lower, as compared to those of the control group $(\mathrm{P}<0.05)$. The mean score of the pain in the intervention group at hours $1,4,10$, and 24 after tonsillectomy were obtained at $8.40,5.74,4.28$, and 2.28 , respectively. On the other hand, in the control group, the above mentioned mean scores were measured at 9.40, 6.80, 4.51, and 2.7 respectively $(\mathrm{P}<0.05)$. Nonetheless, it is noteworthy that no significant difference was observed between the two groups regarding the incidence of nausea and vomiting.

Conclusion: As evidenced by the obtained results, preemptive dexamethasone reduces the post tonsillectomy pain in the first four hours after pediatric adenotonsillectomy. Moreover, it was revealed that it accelerates the initiation of soft-diet feeding without exerting any effect on nausea and vomiting.

Keywords: Dexamethasone, Post-operative Pain, Tonsillectomy 
dof: $10.29252 / \mathrm{ajcm} .26 .3 .131$

\section{تزريق بيشكير انه دكزامتازون براى كاهش درد درعمل لوزهبردارى در كودكان: يك آزمايش بالينى تصادفى شله سه سو كور}

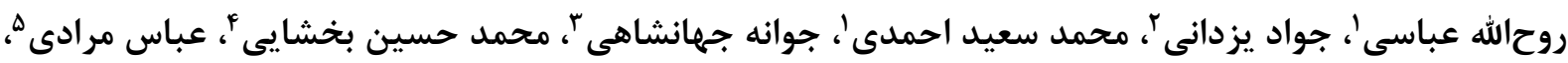
فرناز هاشميان

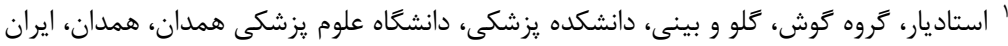

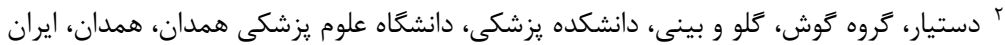

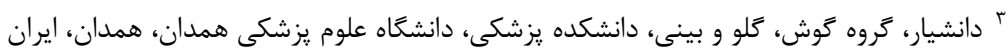

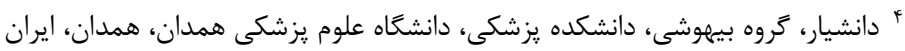

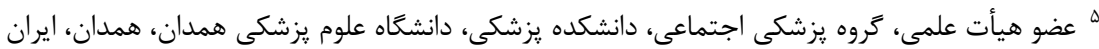
* نويسنده مسئول: فرناز هاشميان، كروه كَش، تلو و بينى، دانشكده يزشكى، دانشَاه علوم يزشكى همدان، همدان، ايران. ايميل: hashemian@umsha.ac.ir

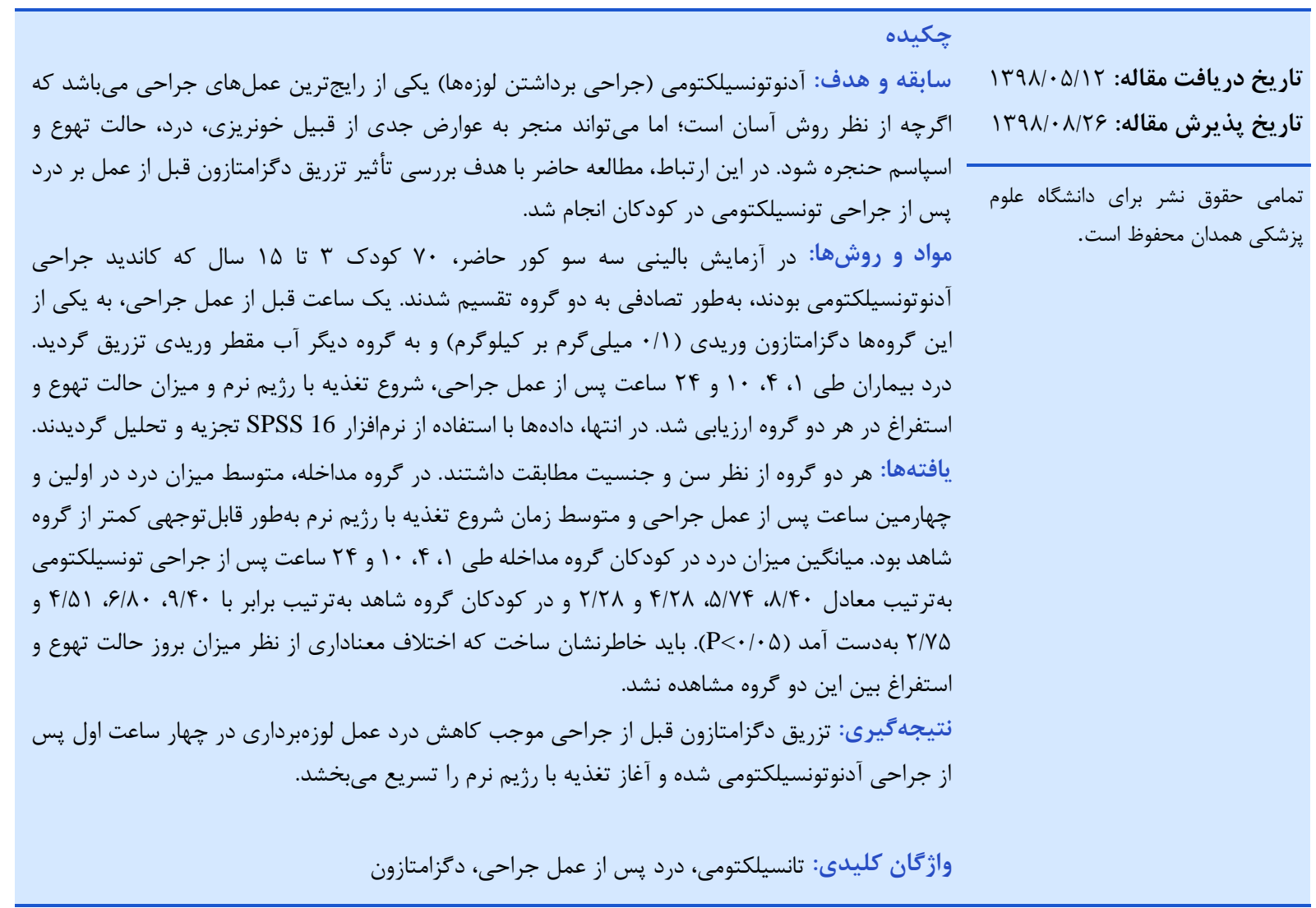

مقلدمه

در بيمارستان بسترى شده و دير ترخيص مى كردند و بيش از

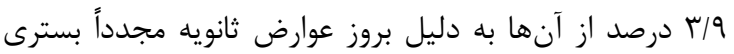

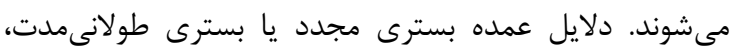

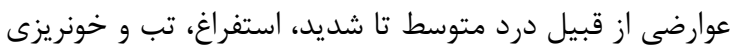

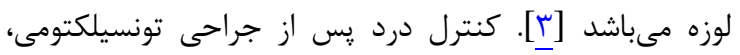

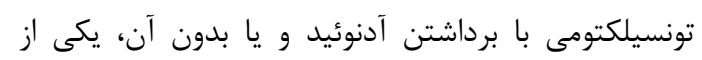

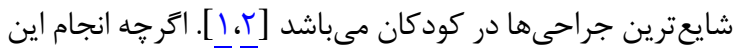

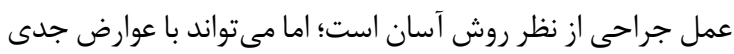

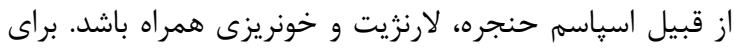

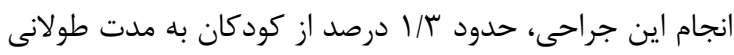




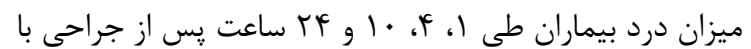

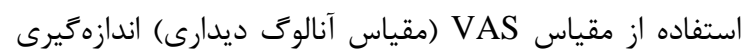

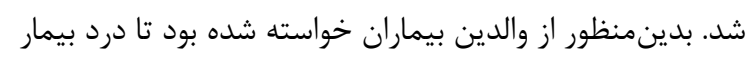

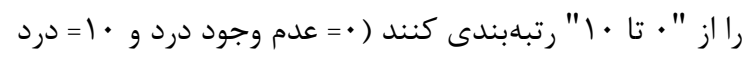

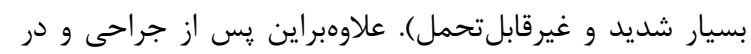

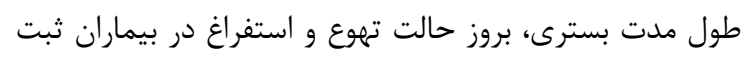

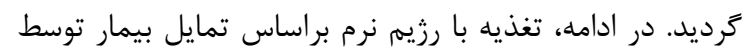

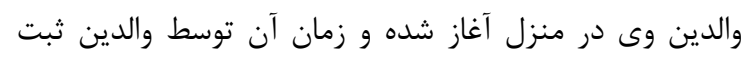

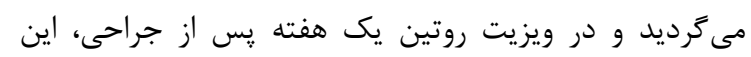

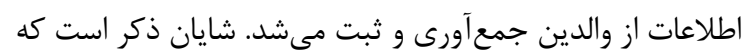

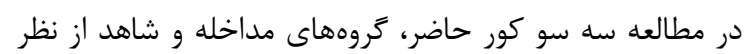

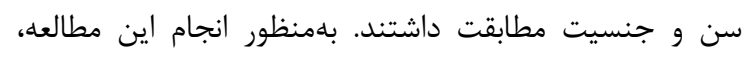

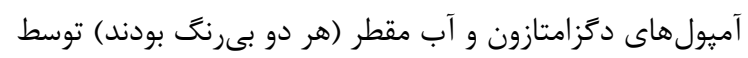

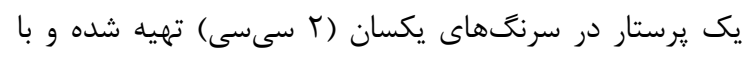

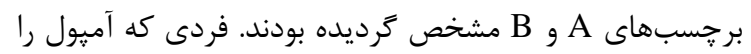

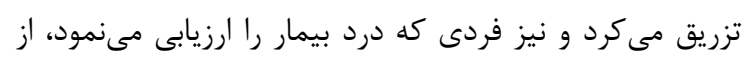

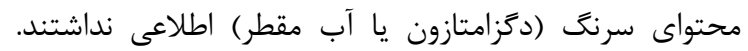

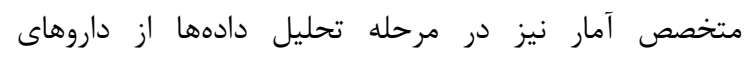

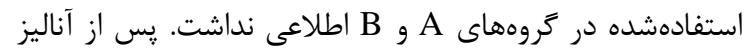

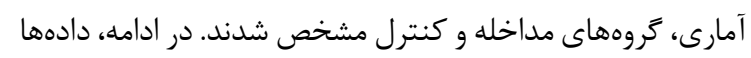

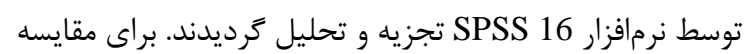

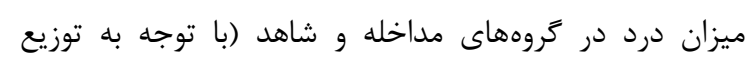

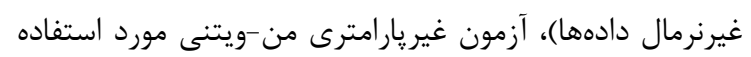

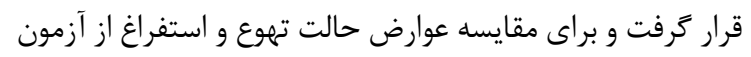

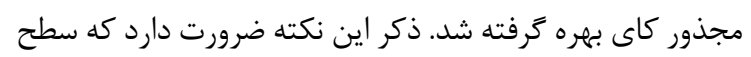

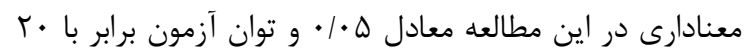

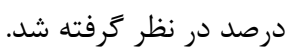

\section{يافته ها}

در اين مطالعه بهطور كلى •V نفر در دو كروه مداخله و شاهد

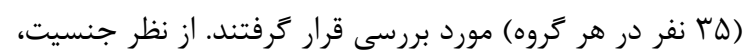

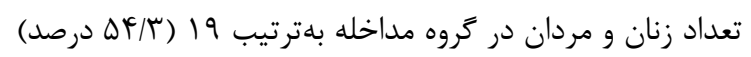

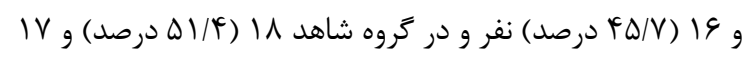
( NN/9)

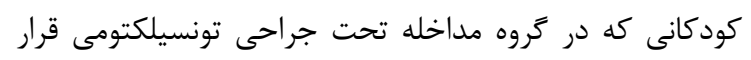

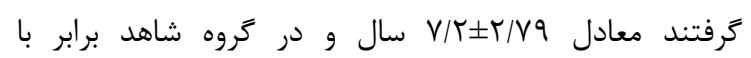
دو

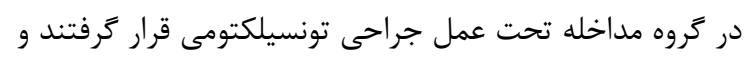

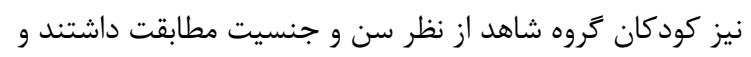

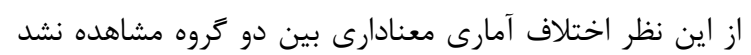

(P>・/・日)

ميانكين و انحراف معيار ميزان درد در كودكان كروه

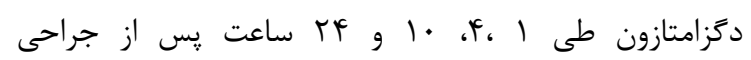

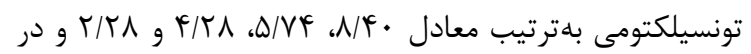

مشكل مهمى است كه هنوز هم در طول درمان كودكان مشاهده

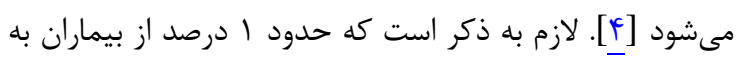

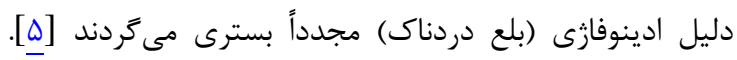

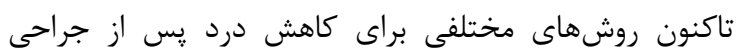

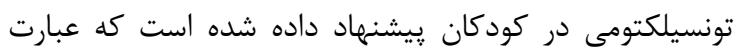

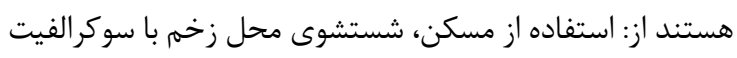

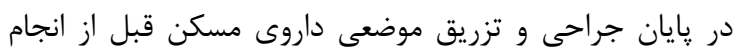

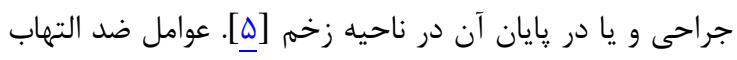

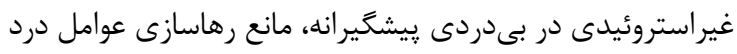

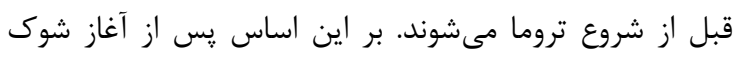

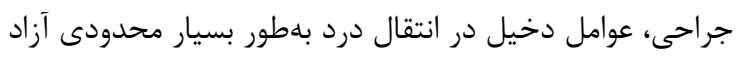

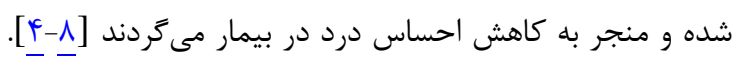

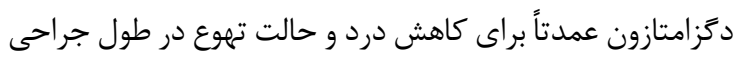

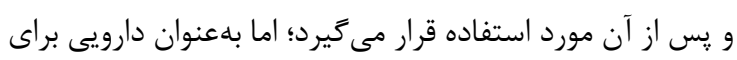

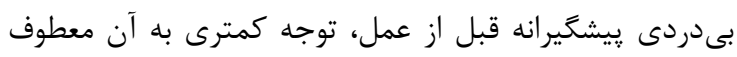

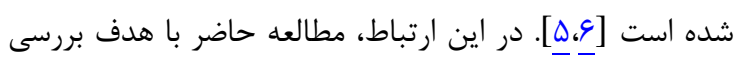

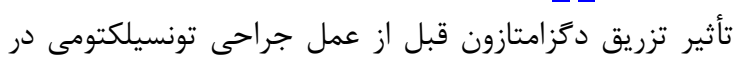

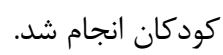

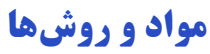

در مطالعه حاضر كه يك آزمايش بالينى سه سو كور مى باشد،

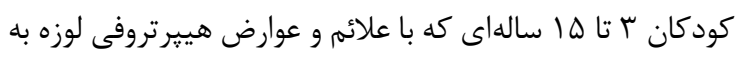

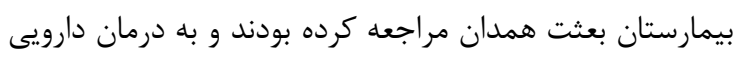

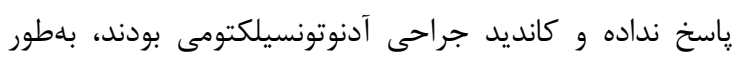

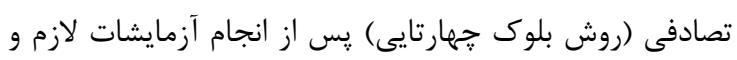

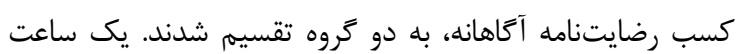

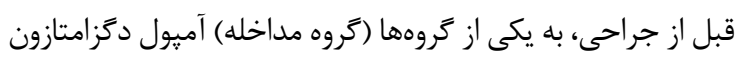

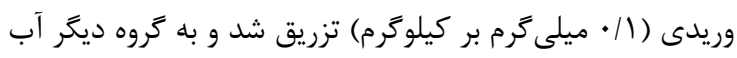

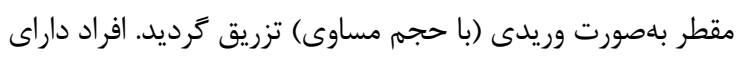

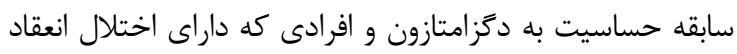
خون بودند، از فرايند مطالعه كنار كذاشته شدارئه

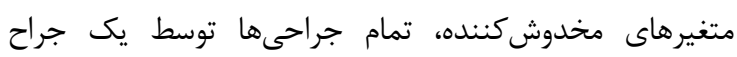

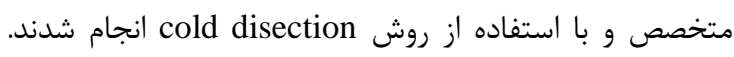

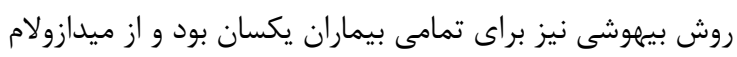

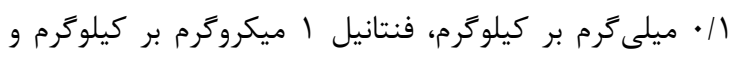

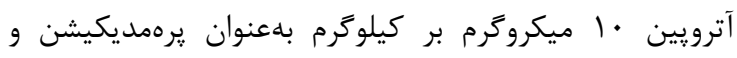

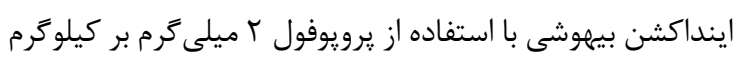

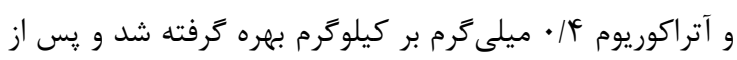

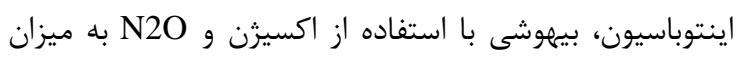

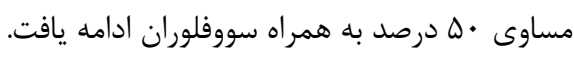

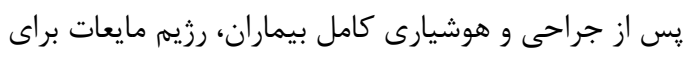

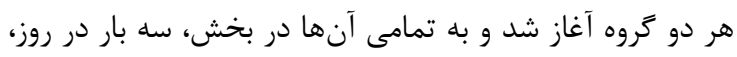

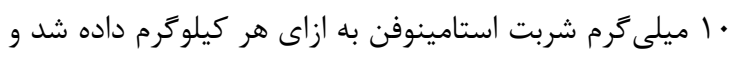

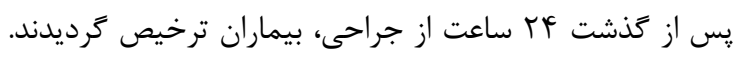


جدول ا: مقايسه ميانكين و انحراف معيار ميزان درد براساس VAS در كروههاى مداخله و شاهد تحت عمل جراحى تونسيلكتومى (آنى

\begin{tabular}{|c|c|c|c|c|c|}
\hline \multicolumn{3}{|c|}{ كروه شاهد ( آب مقطر ) } & \multicolumn{3}{|c|}{ َروه مداخله (دَزامتازون) } \\
\hline سطح معنادارى & انحراف معيار & ميانگين & انحراف معيار & ميانگين & زمان اندازهَيرى \\
\hline $.1 \cdot 1 \mathrm{f}$ & $1 / \cdot r$ & $9 / 4$. & $1 / V \wedge$ & $N / F$. & ا اعت \\
\hline$\cdot / \cdot r$ & $1 / K F$ & s/A. & $1 / \Gamma \wedge$ & $\Delta / V^{\epsilon}$ & T \\
\hline$\cdot / \uparrow \Delta$ & $1 / Q T$ & $F / D \mid$ & $1 / 19$ & $F / T \Lambda$ & •اعت ال ساعت \\
\hline$\cdot 109$ & $1 / \pi \Delta$ & $T / V \Delta$ & $1 / \Delta \varphi$ & T/TA & Fاعت TF \\
\hline
\end{tabular}

جدول r: مقايسه بروز تهوع و استفراغ پِ از جراحى تونسيلكتومى در گروههاى مداخله و شاهد

\begin{tabular}{|c|c|c|c|c|}
\hline \multicolumn{5}{|c|}{ حالت تهوع و استفراغ } \\
\hline سطح معنادارى & تعداد (درصد) كل & تعداد (درصد) & تعداد (درصد) بله & تروه \\
\hline$\cdot \pi$. & ט & T & $(\Lambda / 9) \Gamma$ & دَزامتازون \\
\hline & ه & $(q V / I) T F$ & $(Y / 9))$ & شاهد \\
\hline
\end{tabular}

جدول ب: مقايسه ميانگين و انحراف معيار زمان شروع تغذيه با رزيم نرم پِ از جراحى تونسيلكتومى در گروههاى مداخله و شاهد

\begin{tabular}{|c|c|c|c|}
\hline \multicolumn{4}{|c|}{ زمان شروع تخذيه با رزيم نرم (روز بس از جراحى) } \\
\hline سطح معنادارى & انحراف معيار & ميانظين & تروه \\
\hline.$/ \cdot r$ & $1 / \pi \Delta$ & $r / \Lambda$. & دَزامتازون \\
\hline & $\Delta / V I$ & $91 .$. & شاهد \\
\hline
\end{tabular}

يس از جراحى در مقايسه با كروه شاهد كرديد؛ اما ميزان حالت

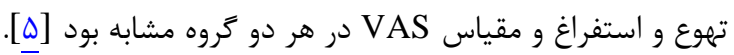

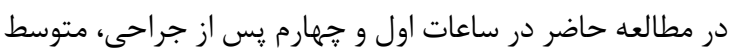

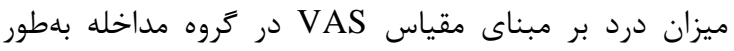

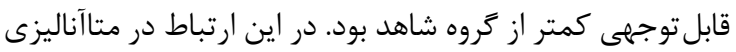

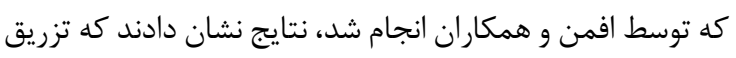
دَزامتازون با دوز منفرد در حين جراحى منجر به كاهش دمان درد

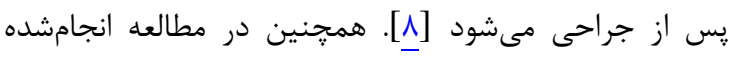

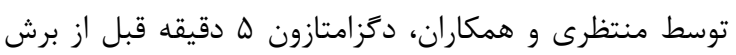

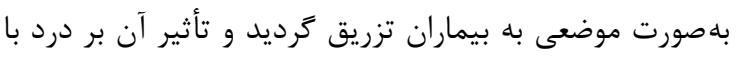

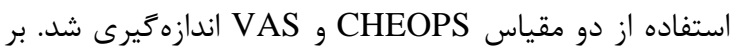

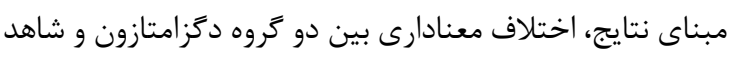

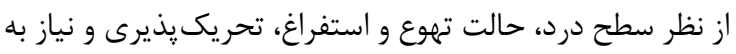

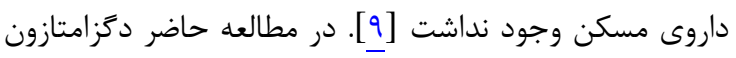

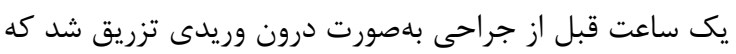

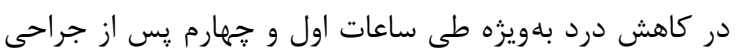

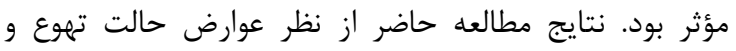

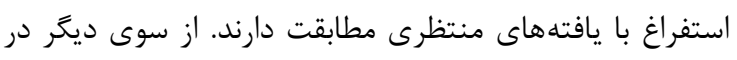

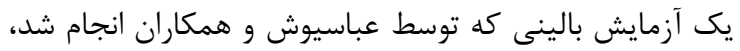

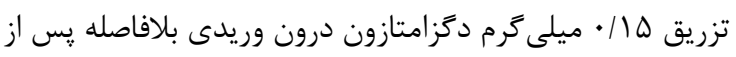

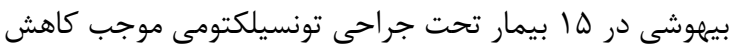

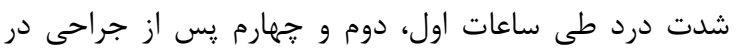

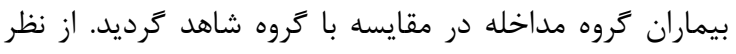

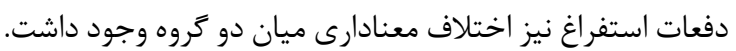

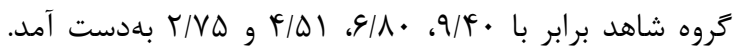

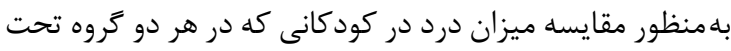

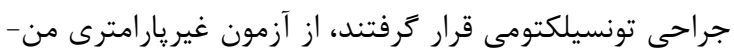

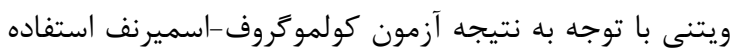

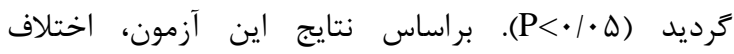

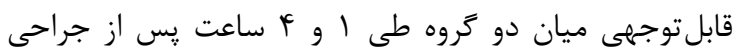

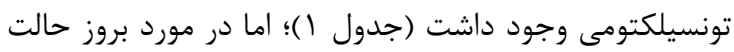

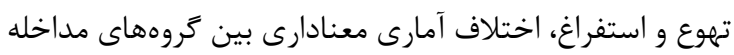

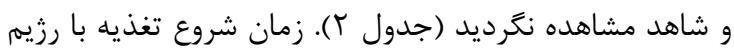

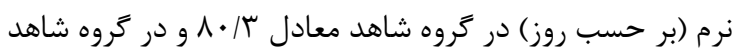

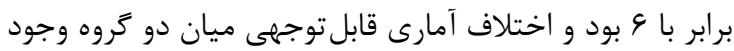

داشت (جدول با بان.

در مطالعه حاضر ميانگين ميزان درد طى ساعات اول و

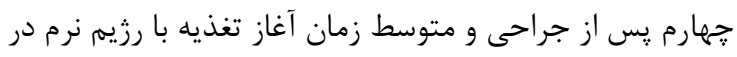

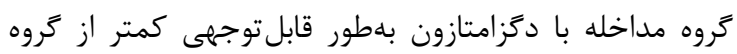

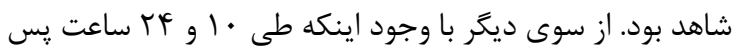

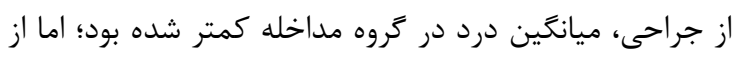

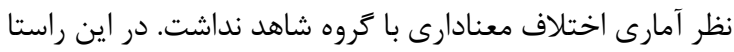

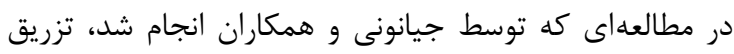

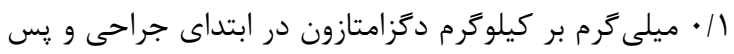
از القاى بيهوشى در كودكانى كه تحت تونسيلكتومى قرى قرار كرفتند، موجب كاهش دوز مصرفى مسكن در طول سه روز دوز اول 
ساعت گֶ از جراحى مؤثرتر باشد.

\section{تشكر و قرو فانى}

مقاله حاضر بركرفته از طرح تحقيقاتى مصوب دانشعاه علوم يزشكى همدان مىباشد. بدينوسيله از حسن همكارى كاركنان

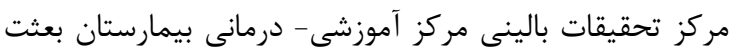

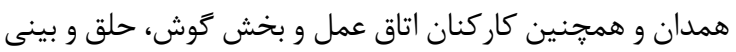
تشكر و قدردانى مى وَردد.

تضاد منافع در اين مطالعه هيج كَنه تعارض منافعى گزارش نشده است.

\section{ملاحظات اخلاقى}

مطالعه حاضر داراى تأييديه اخلاق در يزوهش (با شماره (IR.UMSHA.REC.1394.328 همدان و كد IRCT 2015112024852N2 كارآزمايى هاى بالينى ايران مىباشد.

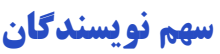

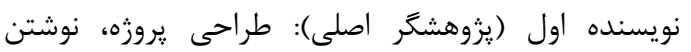

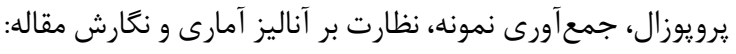

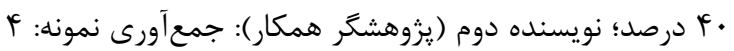

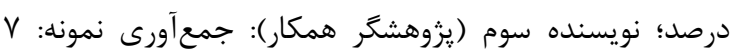

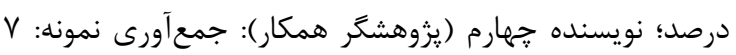

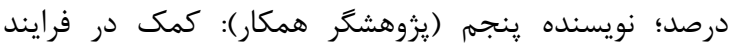
بيهوشى: V درصد؛ نويسنده ششم (يزوهشخر همكار): تحليل

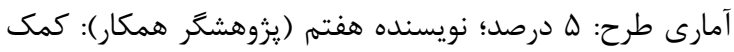

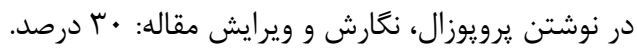

\section{حمايت مالذى}

مطالعه حاضر از سوى مركز تحقيقات بالينى مركز آموزشى - مان

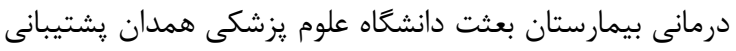
مالى شده است.

\section{REFERENCES}

1. Amani S, Rastiboroujeni M, Abedinzade M. Effects of local injection of bupivacaine and dexamethasone on postoperative pain of adenotonsillectomy. J Shahrekord Univ Med Sci. 2006;8(1):76-81. [Persian]

2. Aouad MT, Siddik SS, Rizk LB, Zaytoun GM, Baraka AS. The effect of dexamethasone on postoperative vomiting after tonsillectomy. Anesth Analg. 2001;92(3):636-40. PMID: 11226091 DOI: 10.1097/00000539-200103000-00015

3. Leong SC, Karkos PD, Papouliakos SM, Apostolidou MT. Unusual complications of tonsillectomy: a systematic review. Am J Otolaryngol. 2007;28(6):419-22. PMID: 17980776 DOI: $10.1016 /$ /.amjoto.2006.10.016

4. Karaaslan K, Yilmaz F, Gulcu N, Sarpkaya A, Colak C, Kocoglu H. The effects of Levobupivacaine Versus Levobupivacaine plus Magnesium infiltration on
متوسط زمان شروع تغذيه دهانى در زروه مداخله بهطور معنادارى كمتر از زروه شاهد بود [ [1]]. نتايج حاصل از مطالعه حاضر از نظر تأثير دگزامتازون بر شدت درد و كاهش زمان شروع تغذيه با رزيم نرم، با يافتههاى عباسيوش و همكاران مطابقت دارد. با اين وجود در مطالعه حاضر از نظر دفعات تكرار حالت تهوع و استفراغ، اختلاف معنادارى ميان دو گروه وجود نداشت

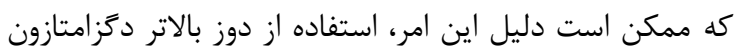
در مطالعه عباسيوش و همكاران باشد. علاوهبراين، در مطالعه كارآزمايى بالينى انجامشده توسط گو و همكاران با هدف مقايسه زروه دگزامتازون درون وريدى، زروه دگزامتازون موضعى و گرووه شاهد، كاهش درد، حالت تهوع و استفراغ و زمان شروع تغذيه دهانى يس از جراحى در بيماران مورد بررسى قرار گرفت. نتايج نشان دادند كه طى ا تا وأ ساعت يس از جراحى، سطح درد در گروهى كه دگزامتازون بهصورت موضعى به آنها تزريق شده بود، بهطور معنادارى كمتر از دو گروه ديخر بود. زمان شروع تغذيه بهونيه دهانى نيز كوتاهتر بود. با اين وجود ميزان بروز حالت تهوع و استفراغ در زروه دگزامتازون موضعى، بيشتر از زروه دگزامتازون درون وريدى بود [11]]. در اين مطالعه گروه دززامتازون درون وريدى با زروه شاهد مورد مقايسه قرار زرفت كه نتايج از نظر تأثير دَزامتازون بر كاهش سطح درد و كوتاهشدن زمان شروع تغذيه با رزيم نرم، با يافتههاى گو و همكاران مطابقت دارند. از سوى ديخر در مطالعه انجامشده توسط نجيب و همكاران، تزريق درون وريدى دگزامتازون قبل از عمل جراحى تونسيلكتومى منجر به كاهش درد گي از عمل، بهبود تغذيه و كاهش طول مدت

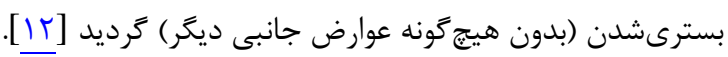

\section{نتيبحه تَيرى}

تزريق ييشخيرانه درون وريدى دگزامتازون با دوز / / ميلى گرم بر كيلوگرم در كودكانى كه تحت عمل جراحى آدنوتونسيلكتومى قرار گرفتند موجب كاهش درد در جههار ساعت اول يس از اتمام عمل جراحى و تسريع آغاز تغذيه با رثيم نرم در بيماران گرديد. در اين ارتباط توصيه مىشود كه در مطالعات آتى،

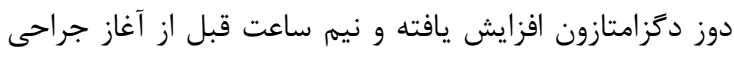

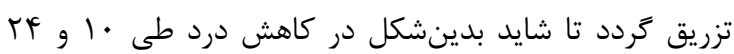

postoperative analgesia and Laryngospasm in pediatric Tonsillectomy Patients. Int J Pediatr Otorhinolaryngol. 2008;72(5):675-81. PMID: 18325601 DOI: 10.1016/j.ijporl. 2008.01 .029

5. Giannoni C, White S, Enneking FK. Does dexamethasone with preemptive analgesia improve pediatric Tonsillectony pain? Otolaryngol Head Neck Surg. 2002;126(3):307-15. PMID: 11956540 DOI: $10.1067 / \mathrm{mhn} .2002 .122700$

6. Sampaio AL, Pinheiro TG, Furtado PL, Araújo MF, Olivieira CA. Evaluation of early postoperative morbidity in pediatric tonsillectomy with the use of sucralfate. Int J Pediatr Otorhinolaryngol. 2007;71(4):645-51. PMID: 17275926 DOI: 10.1016/j.ijporl.2006.12.016

7. Ugur MB, Yilmaz M, Altunkaya H, Cinar F, Ozer Y, Beder L. Effects of intramuscular and peritonsillar injection of 
tramadol before tonsillectomy: a double blind, randomized, placebo- controlled clinical trial. Int $J$ Pediatr Otorhinolaryngol. 2008;72(2):241-8. PMID: 18079005 DOI: 10.1016/i.ijporl.2007.11.002

8. Afman CE, Welge JA, Steward DL. Steroids for posttonsillectomy pain reduction: Meta-analysis of randomized controlled trials. Otolaryngol Head Neck Surg. 2006; 134(2):181-6. PMID: 16455362 DOI: 10.1016/j.otohns. 2005.11.010

9. Montazeri K, Okhovat A, Honarmand A, Safavi MR, Ashrafy L. Pre-incisional infiltration of tonsils with dexamethasone dose not reduce posttonsillectomy vomiting and pain in children. Saudi J Anaesth. 2009;3(2):53-6. PMID: 20532103 DOI: $10.4103 / 1658-354 X .57874$
10. Abbasivash R, Mahoori AR, Ahmadi Roozbehani N, Ebadi $\mathrm{S}$, Saane $\mathrm{SH}$. Investigating the effects of interavenous dexametasone reduction in post tonsillectomy and adenotoncilectomy sore throat and vomiting. J Urmia Univ Med Sci. 2015;26(1):56-63. [Persian]

11. Gao W, Zhang QR, Jiang L, Geng JY. Comparison of local and intravenousdexamethasone for postoperative pain and recovery after tonsillectomy. Otolaryngol Head Neck Surg. 2015;152(3):530-5. PMID: 25605698 DOI: 10.1177/ 0194599814567856

12. Najeeb T, Bangash K, Nasarullah M, Husain A. Role of preoperative dexamethasone in reduction of post tonsillectomy pain. J Islamabad Med Dent Coll. 2016; 5(2):67-70. 